\title{
A Review on the Role of Climate Smart Agriculture for Sustainable Crop Production
}

\author{
Sewnet Getahun Mesfin \\ Collage of Agriculture and Natural Resource, Department of Plant Science, Debre Markos University, Debre \\ Markos, Ethiopia
}

\begin{abstract}
Almost all sectors, especially agriculture are highly climate sensitive and thus climate change have both direct and indirect negative impacts on production systems. Changes in climate, increased frequency and intensity of climate shocks (such as drought, flooding and extreme temperatures) as well as changing distribution and timing of rainfall are major factors which negatively affect sustainable crop production. This needs the solution to feed rapidly increasing population in the world especially African countries due to their less ability to cope the climate change. Therefore, one of the proposed means is climate smart agriculture. CSA is defined by three objectives: firstly, increasing agricultural productivity to support increased incomes, food security and development; secondly, increasing adaptive capacity at multiple levels (from farm to nation) and thirdly, decreasing greenhouse gas emissions and increasing carbon sinks/sequestration. There are many agricultural practices which are important for this approach some of them include conservation agriculture, agro forestry, soil and water conservation techniques and irrigation practices. CSA integrates climate change into the planning and implementation of sustainable agriculture and informs priority-setting. Identifying appropriate ways to incentivize the uptake of climate smart alternatives is a key priority to improve productivity and reduce yield variability.
\end{abstract}

Keywords; Conservation Agriculture, Agro-forestry, Carbon Sequestration, Adaptive Capacity

DOI: $10.7176 / \mathrm{JBAH} / 9-12-02$

Publication date:June $30^{\text {th }} 2019$

\section{Introduction}

Climate change is a change in the state of the climate that can be identified by changes in the mean and/or the variability of its properties and that persists for an extended period, typically decades or longer. It refers to any change in climate over time whether due to natural variability or as a result of human activity" (IPCC, 2007). The world's climate is changing and will continue to change until drastic action is taken to combat the effect of it. Global average surface temperatures have increased by $0.74^{\circ} \mathrm{C}$ over the past 100 years with the biggest increase of $0.55^{\circ} \mathrm{C}$ occurring over only the past 30 years (Mertz, 2009). Worldwide Temperature is projected to increase by an additional $1.5-5.8^{\circ} \mathrm{C}$ by the end of the 21 st century (Rosenzweig et al., 2001).

Increased climate variability in the coming decades will increase the frequency and severity of floods and droughts and will increase production risks for agriculture especially crop production and reduce their coping ability (Thornton and Gerber, 2010). Climate change could have serious effects on agricultural production in worldwide particularly in Africa (FAO, 2014). Recent projections suggest global population will also grow from a current 7 billion to more than 9 billion people in 2050 (UNESCO, 2012). This is a huge challenge to feed 2 billion additional people in 2050 . Given both food consumption trends and population growth is expected that a 60 percent increase in global agricultural production will be required by 2050 and particularly in developing countries and most especially in dry land agro ecologies (FAO, 2012a). Consequently, there is a need to simultaneously improve agricultural productivity and reduce yield variability over time under adverse climatic conditions. Therefore, agriculture in developing countries must undergo significant transformation to meet the growing population and interconnected challenges of food insecurity and climate change (FAO, 2010).

A proposed means to achieve sustainable agricultural productivity is increased adoption of a 'climate-smart agriculture' (CSA) approach (FAO, 2010). CSA is composed of three main pillars: sustainably increasing agricultural productivity and incomes; adapting and building resilience to climate change and reducing and/or removing greenhouse gases emissions relative to conventional practices (FAO, 2013). The agricultural technologies and practices that constitute a CSA approach are largely coinciding with those of sustainable agriculture and sustainable intensification. Therefore, the objective of this paper is to review on the role of climate smart agriculture and its practices for sustainable crop production. In this review paper I attempt to find common ideas and concepts based on peer reviewed articles showing the climate smart agriculture and their technologies and practices for sustainable crop production.

\section{Climate Smart Agriculture}

\subsection{Principles of Climate Smart Agriculture}

Climate smart agriculture is a new approach, a way to guide the needed changes of agricultural systems, given the necessity to jointly address food security and climate change (Grainger-Jones, 2011). It is a concept developed by 
FAO, is an approach to developing the technical, policy and investment conditions to achieve sustainable agricultural development for food security under climate change (FAO, 2013). It integrates the three dimensions of sustainable development (economic, social and environmental) by jointly addressing the food security, ecosystems management and climate change challenges. It is comprised of three main pillars:

$\checkmark$ Sustainably increasing agricultural productivity and incomes;

$\checkmark$ Adapting and building resilience to climate change;

$\checkmark$ Reducing and/or removing greenhouse gases emissions, where possible.

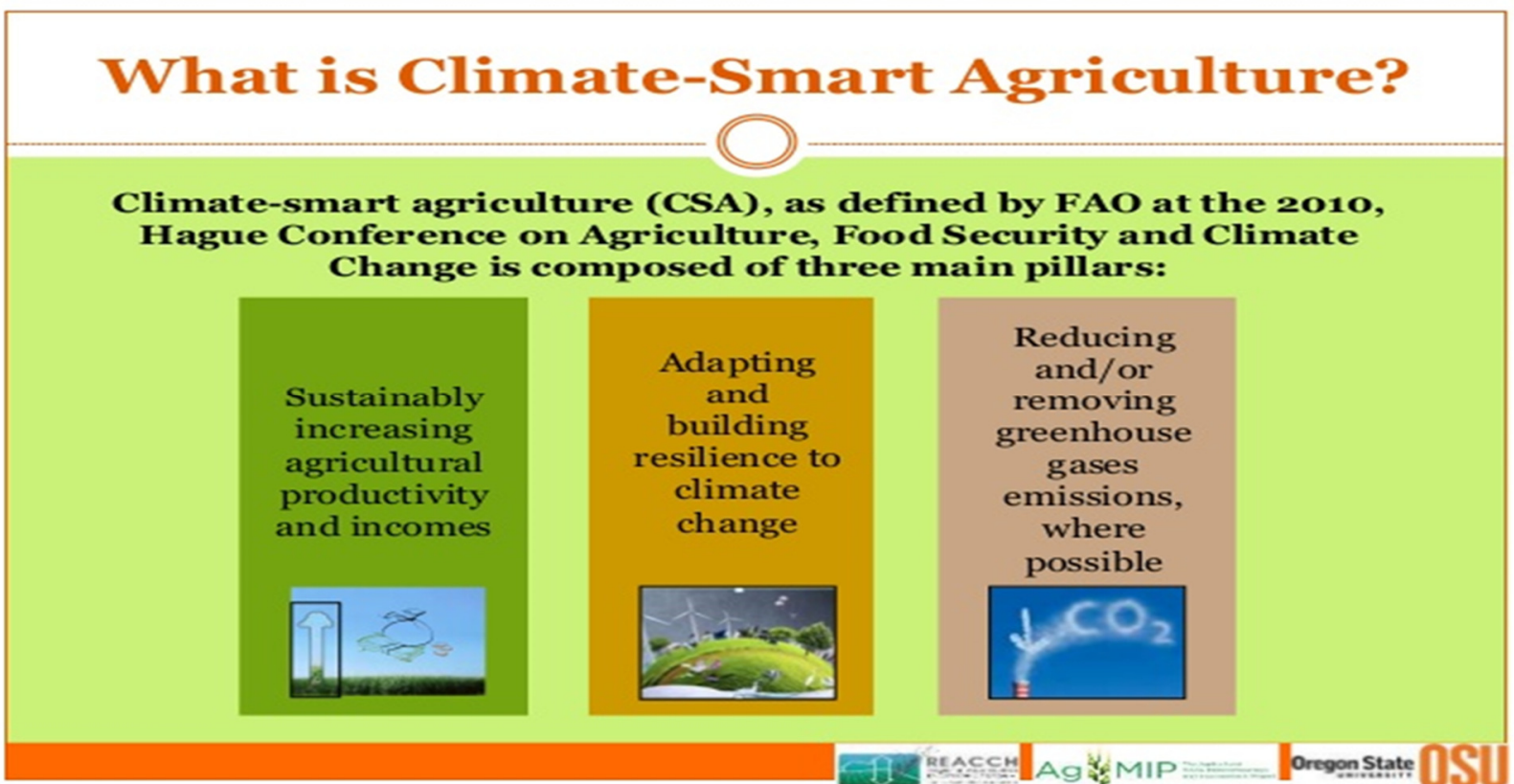

Figure1. Three main pillers of climate smart agriculture (Adopted from FAO, 2010).

Increasing productivity as well as reducing costs through increased resource-use efficiency is important means of attaining agricultural growth. CSA aims to sustainably increase agricultural productivity and incomes from crops, livestock and fish, without having a negative impact on the environment. This, in turn, will raise food and nutritional security. A key concept related to raising productivity is sustainable intensification https://csa.guide/csa/. It is also possible to reduce and even avoid the negative impacts of climate change but it requires formulating and implementing effective adaptation strategies. Given the site-specific effects of climate change, together with the wide variation in agro-ecologies and farming the most effective adaption strategies will vary even within countries. A range of potential adaptation measures have already been identified which can provide a good starting point for developing effective adaptation strategies for any particular site (IPCC, 2007). CSA aims to reduce the exposure of farmers to short term risks, while also strengthening their resilience by building their capacity to adapt and prosper in the face of shocks and longer-term stresses. Particular attention is given to protecting the ecosystem service and ecosystem which provide to farmers and others. These services are essential for maintaining productivity and our ability to adapt to climate changes https:/csa.guide/csa/. The most important strategies for the climate change adaptation for sustainable crop production include; plants tolerance to shocks such as temperature extremes, drought, flooding and pests and diseases. It also regulates the length of growing season/production cycle and the response to inputs such as fertilizer, water and nutrient. The preservation of genetic resources of crops and their wild relatives is therefore fundamental in developing resilience to shocks, improving the efficient use of resources, shortening production cycles and generating higher yields (and quality and nutritional content) per area of land (FAO, 2010).

In many developing countries governments are now formulating nationally appropriate mitigation actions which identify agriculture as an important sector. Today, boosted by new studies that indicate agriculture can be a cost-effective emissions reduction strategy and identify many synergies between adaptation and mitigation, climate-smart agriculture is becoming the new paradigm (FAO, 2010). Mitigation options for agriculture are generally divided into three broad categories of practices: (1) activities that increase carbon stocks above and below ground; (2) actions that reduce direct agricultural emissions (carbon dioxide, methane, nitrous oxides) anywhere in the lifecycle of agricultural production; and (3) actions that prevent the deforestation and degradation of high-carbon ecosystems to establish new agricultural areas (Wollenberg et al., 2012b).

\subsection{Climate smart agriculture approaches and practices for sustainable crop production}

The identification and implementation of agricultural practices and technologies that enhance productivity in a 
sustainable manner, could contribute to better management of natural resources, including genetic resources which are essential for coping with climate change (FAO, 2015), and thus reduce the impacts of climate change. Those practices should ideally equally contribute to adaptation and mitigation practices. Practices that have the potential to enhance sustainable productivity, increase resilience and food security in crop production can be organized around five main themes: (i) maintaining healthy soil to enhance soil-related ecosystem services and crop nutrition, including through integrated nutrient management; (ii) cultivating a wider range of species and varieties in associations, rotations and sequences; (iii) using quality seeds and planting materials of well adapted, high-yielding varieties; (iv) adopting integrated pest management to reduce impacts of pests, diseases and weeds; and (v) managing water efficiently, including soil moisture and, the case being, irrigation practices (FAO, 2014).

According to Tantely et al. (2015) climate smart agriculture is presented recently as a solution for food insecurity and climate change impacts. In developing countries, different sustainable agricultural practices are important in order to increase crop yield, to maintain soil fertility and to increase household income. These practices are conservation agriculture (CA), agroforestry, water conservation, irrigation system, rice systems that reduce methane emissions, improved management of soil carbon as well as breeding plants adapted for future climate conditions. These technologies and practices are referred to as climate smart agriculture (CSA).

\subsubsection{Conservation Agriculture}

Conservation agriculture $(\mathrm{CA})$ is a system of farming that employs a minimum of techniques that disturb the soil for planting; maintains permanent soil cover via crop residues, mulches, or cover crops and employs crop rotation (FAO, 2010). Milder et al. (2011) define CA as a farming approach that fosters natural ecological processes to increase agricultural yields and sustainability by minimizing soil disturbance, maintaining permanent soil cover and diversifying crop rotations. Conservation Agriculture (CA) is a term encompassing farming practices which have three key characteristics:

$\checkmark \quad$ Minimal mechanical soil disturbance (i.e. no tillage and direct seeding);

$\checkmark$ Maintenance of a mulch of carbon-rich organic matter covering and feeding the soil (e.g. straw and/or other crop residues including cover crops) and

$\checkmark$ Rotations or sequences and associations of crops including trees which could include nitrogen-fixing legumes.

Management of soil fertility and organic matter and improvement of the efficiency of nutrient inputs enables more to be produced with proportionally less fertilizers (FAO, 2010).This system has several goals, including preventing soil erosion, maintaining soil structure, increasing organic matter content, and improving water infiltration and retention, all of which have the potential to increase long-term yields and reduce yield variability even in the face of climate change (Bot and Benites, 2001). Long-term research by the International Maize and Wheat Improvement Center (CIMMYT) in El Batan, Mexico showed that over a 10-year period (1996-2006) grain yields for both wheat and maize were consistently higher and more stable when grown under the full conservation agriculture recommended practices when compared to conventional tillage systems (Erenstein et al., 2012).

According to Govaerts et al. (2005) average maize yield over 1991-2004 was 48 percent higher and that of wheat was 27 percent higher in the no-till crop rotation system with (full or partial) residue retention compared to the plots with conventional till, continuous cropping, and no residue retention. Alvarez and Steinbach (2009) reviewed 35 different field experiments conducted in the region and found that water infiltration and aggregate stability were significantly higher in soils under limited tillage, but they found few other positive effects. Thierfelder et al. (2013) also reported that, average maize grain yields from 1997 to 2009 were $50 \%$ greater under conservation agriculture than under continuous maize with conventional tillage and residue removal, an average yield benefit of 1.8 tons per ha. Yields were also more stable, the drought-buffering benefit of CA was particularly apparent in 2009, an unusually dry year.

Conservation Agriculture also contributes to adaptation to climate change by reducing crop vulnerability. The protective soil cover of leaves, stems and stalks from the previous crop shields the soil surface from heat, wind and rain, keeps the soil cooler and reduces moisture losses by evaporation (FAO, 2010). In drier conditions, it reduces crop water requirements, makes better use of soil water and facilitates deeper rooting of crops, in extremely wet conditions. CA facilitates rain water infiltration which improves water use efficiency and buffers crops against drought, reducing soil erosion and the risk of downstream flooding. Mulch cover also buffers the soil against temperature extremes and minimizes the outbreak of pests and diseases (FAO, 2014).

Conservation agriculture is also an interest because of its potential for climate change mitigation in the form of increased carbon sequestration (FAO, 2014). Some studies have shown that conservation agriculture increases the amount of carbon stored in soils, thus it may have some mitigation potential (La Scala et al., 2006). The results showed that soil erosion was six times lower under no-till and three times lower under crop-pasture rotation when compared to conventional tillage. Soil organic matter accumulation was also higher under no-till when crop residues were left on the soil and even higher under the crop-pasture rotation systems. Carbon stocks in the 0-60 $\mathrm{cm}$ soil layer were 50\% higher (36 Mg C per ha) after 18 years under CA than those under continuous maize with conventional tillage and residue removal (Thierfelder et al., 2013). Sisti et al. (2004) analyzed the differences in 
carbon levels in soils under no-till versus conventional tillage under several different crop rotation systems after a 13-year experiment in southern Brazil. Avoidance of tillage minimizes occurrence of net losses of carbon dioxide by microbial respiration and oxidation of the soil organic matter and builds soil structure and bio-pores through soil biota and roots. Maintenance of a mulch layer provides a substrate for soil-inhabiting microorganisms which helps to improve and maintain water and nutrients in the soil. This also contributes to net increase of soil organic matter derived from carbon dioxide captured by photosynthesis in plants, whose residues above and below the surface are subsequently transformed and sequestered by soil biota (FAO, 2010).

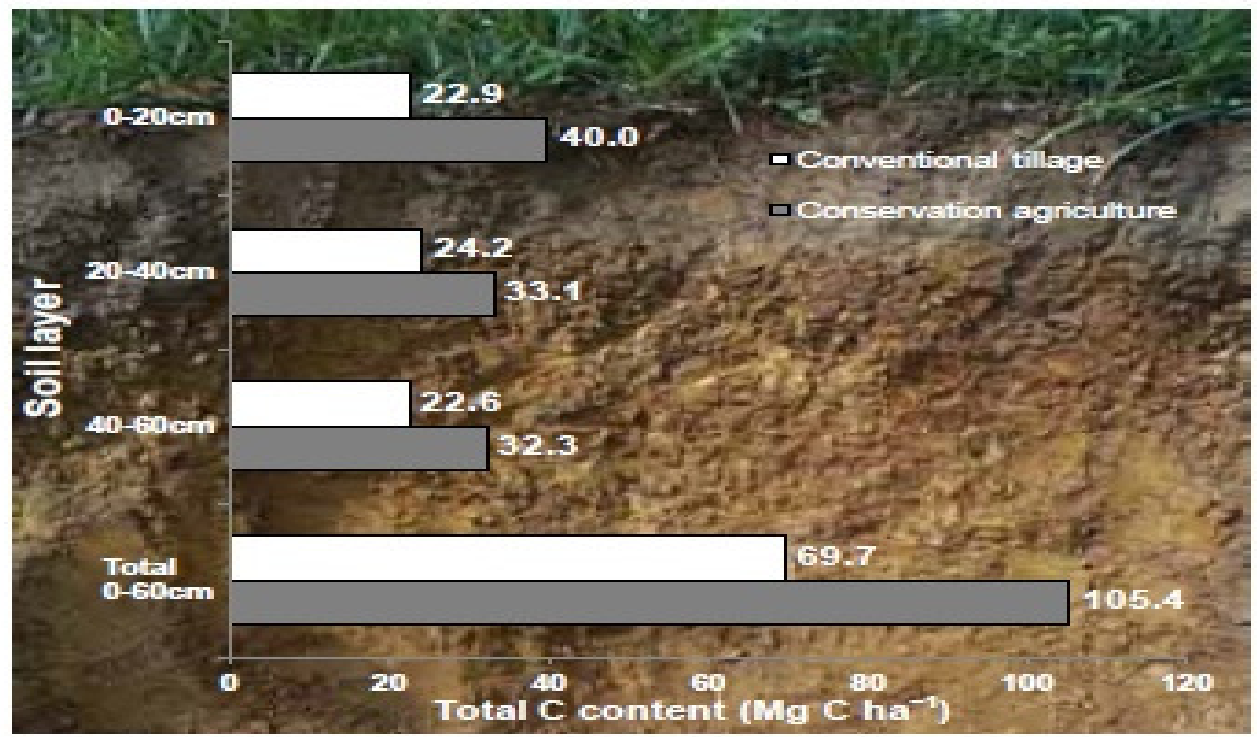

Figure 2 the effect of zero-till with residue retention and wheat-maize crop rotation (CA) and conventional tillage with crop removal and continuous maize (CT) on total soil C content in El Batán, Mexico (Data from Dendooven et al., 2012).

\subsubsection{Agro-forestry}

Agro-forestry refers to land use practices in which woody perennials are deliberately integrated with agricultural crops, varying from very simple and sparse to very complex and dense systems. It is estimated that trees occur on 46 percent of all agricultural lands and support 30\% of all rural populations (Zomer et al., 2009). It embraces a wide range of practices (e.g. farming with trees on contours, intercropping, multiple cropping, bush and tree fallows, establishing shelter belts and riparian zones/buffer strips with woody species etc.) which can improve land productivity providing a favorable micro-climate, permanent cover, improved soil structure and organic carbon content, increased infiltration and enhanced fertility reducing the need for mineral fertilizers (Garrity, 2004).

The use of trees and shrubs in agricultural systems help to tackle the triple challenge of securing food security, mitigation and reducing the vulnerability and increasing the adaptability of agricultural systems to climate change. Trees in the farming system can help increase farm incomes and can help diversify production and thus spread risk against agricultural production or market failures. This will be increasingly important as impacts of climate change become more pronounced (FAO, 2010). Trees and bushes may also yield products that can either be used for food consumption (fruits), fodder, fuel and building materials. Firewood or sold for cash, leading to greater average household income and contributing to household risk management via reduced income variability (Ajayi et al., 2006). Soto-Pinto (2000) studied outputs from shade grown coffee production in Mexico and found that shaded groves had yields $23-38 \%$ higher. Other researchers have also shown that shade can increase the sustainability of these crops and in the case of coffee may actually help increase yields particularly in a situation of increasing climatic extremes (Lin et al., 2008).

Agro-forestry also can play a significant role in adaptation to climate change: deep roots enable trees to access more water, increase soil porosity, reduce run-off and increase soil cover (which increases infiltration and thus water-use efficiency), contribute organic matter to the soil via leaf litter, lower the temperature under the canopy (thus creating a buffer against temperature increases) and produce higher value products that can strengthen farmers' income levels (Verchot et al., 2007). It also generates adaptation benefits through its impact on reducing soil and water erosion, improving water management and in reducing crop output variability (Ajayi et al., 2006). Shade for agro-forestry systems also acts as a buffering mechanism to temperature variation and storm events (Lin, 2011). Trees and shrubs can enrich biodiversity in the landscape and increase ecosystem stability (FAO, 2010).

Agro forestry systems tend to sequester much greater quantities of carbon than agricultural systems without trees (FAO, 2010). Planting trees and bushes also increase carbon sequestration above and belowground, thereby contributing to greenhouse gas mitigation (Verchot et al., 2007). It is relatively efficient and cost effective 
compared to other mitigation strategies and provides a range of co-benefits important for improved farm family livelihoods and climate change adaptation. It is therefore important both for climate change mitigation as well as for adaptation through reducing vulnerability, diversifying income sources, improving livelihoods and building the capacity of smallholders to adapt to climate change (FAO, 2010).

\subsubsection{Soil and water conservation structures}

The goal of soil and water conservation structures is to reduce run-off and soil erosion, which can help to increase yields, especially on steeply sloped land. Structures for soil and water conservation includes terraces, bunds, live barriers, contour cultivation, grass strips, diversion ditches, check dams, and irrigation pits. Terraces are earth embankments constructed at a right angle in to order to create a flat surface for cultivation even on a hillside (Obalum at al., 2011). Bunds, also called contour banks are small banks built along the contour of a slope that help to hold in ponded water. Both terraces and bunds are often combined with contour cultivation, which consists of cultivating the land on or close to the contour, and at right angles to surface water flow. Each furrow acts as a small dam, slowing down the movement of run-off over the soil and giving the water time to infiltrate into the soil (Obalum et al., 2011). Farmers with support from Oxfam began building stone contour bunds to harvest rainwater. The bund allows water to spread evenly through the field and infiltrates the soil and also prevents soil and organic matter being washed away. This practice increases the barley productivity up to $1500 \mathrm{~kg} / \mathrm{ha}$ (Reij, 2009). Constructing stone bunds along contours are an effective way to harvest water and decrease runoff erosion. When combined with other land management techniques such as zai" pits (shallow bowls filled with compost or manure in which crops are planted) yield of millet or sorghum can also double as compared with unimproved land and reach more than 1t per ha (Bayala et al., 2012).

Pretty et al. (2006) reviewed 286 projects of various types in 57 developing countries, all aimed at promoting conservation and sustainable agricultural practices. Results showed that these practices increased production on 12.5 million of the 37 million hectares reviewed that the average yield increase was $79 \%$, and that the average increase in water-use efficiency was 257 percent. Posthumus (2005) stated that the primary benefit of terracing is increased water availability in the terraced land, which can increase productivity. He also showed that grain yields were $79 \%$ higher when terraces were used on hills with a $25 \%$ slope in one study region (Pacucha). But economic profitability of soil and water conservation structures revealed that profitability varies dramatically based on type of structure, level of rainfall, degree of slope, type of soil, type of crop, local market conditions and many other factors (Jansen et al., 2006).

Soil and water conservation not only increase incomes but also facilitate climate change adaptation. Improved land management often leads to increased tree cover and improved soil fertility and ground water levels. This allows farmers to grow vegetables on small plots near wells, thus increasing both their income and diet diversity. The use of stone bunds can thus lead to nutritional benefits, while also allowing farmers to cope with changing weather (adaptation to wetter or drier climates). Soil fertility is often improved as a result of more manure being applied and increased tree cover contributes further mitigation benefits (Campbell et al., 2014).

\subsubsection{Small-scale irrigation}

Irrigation reduces farmers' reliance on natural rainfall patterns which in general reduces vulnerability to climatic variation. Worldwide irrigated land comprises $15 \%$ of total cropped area but supplies $36 \%$ of production (Howell, 2001). The disproportionate share of production on irrigated land is even greater for some middle-income countries, $70 \%$ of grain in China and $50 \%$ of grain in India is produced on irrigated land, while in Brazil only $5 \%$ of cropped land is irrigated but this accounts for $35 \%$ of production (Laclau and Laclau, 2009). Those countries with the highest cereal production are also those with the highest proportion of irrigated land (San Martin, 2002). This indicates that irrigation significantly increases yields though the amount of this increase varies widely by crop irrigation system and geographic location. Irrigation not only helps increase yields on existing land, it also enables cultivation of land that would not be arable without irrigation technology. Today irrigation is practiced on $20 \%$ of the agricultural land in developing countries but can generate $130 \%$ more yields than rain-fed systems. The expansion of efficient management technologies and methods especially that relevant to smallholders is fundamental (FAO, 2010). Geerts et al. (2008) tested the effects of deficit irrigation at one site with adequate rainfall during the crucial growth stage, deficit irrigation had no effect on yields but that yields were $147 \%$ higher under deficit irrigation at the site with low rainfall. Given the emphasis here on climate change and agriculture, it is particularly important to consider the water-use efficiency of irrigation systems, since that efficiency has major implications for how effectively irrigation systems can maintain production in the face of drought (McCarthy, 2014).

\subsection{Climate smart agriculture implementation}

Climate-smart interventions are highly location-specific and knowledge-intensive. However, implementing this approach is challenging, partly due to a lack of tools and experience. A good understanding of what these barriers are and how they impinge on adoption of CSA practices is essential. Considerable efforts are required to develop the knowledge and capacities to make CSA a reality. An identification and critical analysis of the factors that limit 
adoption of CSA practices and a policy framework will enable policy makers to come up with concrete actions to scale up/ out adoption of CSA practices in developing countries (Barnard et al., 2015). Dobermann and Nelson (2013) offered possible solution to this by suggesting the implementation of the following processes.

1) Diagnosis: which entails understanding the context in which an effort or intervention will be implemented and its links to global agro-ecological knowledge.

2) Contextualized principles: by identifying the right economic, social and ecological principles of relevance to farmers' needs.

3) Getting it right locally: through empowering local communities to improve the performance of the farming system based on agro-ecological principles and local preferences.

4) Scaling and support: by expanding the scope of the effort or intervention (in terms of numbers of people involved and the size of the territory) and create the necessary value chains, services, support systems and selfsustained business models.

5) Evidence: through monitoring and documenting the performance, and learning to enrich the local and global knowledge base to influence policies that will support further implementation.

According to Knaepen et al. (2015) there are also four processes to implement CSA in farmer's level.

1. Implementation of CSA practices is based on knowledge. A critical element in supporting the spread of knowledge as well as in supporting the scaling-up of efforts is awareness among all stakeholders (i.e., their understanding of the climate problem, solutions and practices available). Moreover, gaps in knowledge require increased research on context-specific CSA methods, based on risk profiling, vulnerability and readiness assessments. In addition, indigenous knowledge should feed directly into research findings (FAO, 2013).

2. Multi-stakeholder approach, involving all actors, ranging from businesses to civil society to farmers, can offer an effective way forward for CSA implementation. Through alliances, gatherings, conferences, organizations, these actors should be offered the platforms to communicate approaches and to scale-up indigenous knowledge. Scaling-up local capacities for adaptation, mitigation and resilience-building, requires strengthened multistakeholder cooperation (https://ccafs.cgiar.org/publications/).

3. Governments are in the position to create an enabling environment, by mainstreaming climate change into agricultural policies. These policies should be based on mapping of lessons learned to be disseminated to other parts of the country or region. On the basis of a better-coordinated governance structure and institutional arrangements programs are then designed, putting forward concrete guidelines for implementation.

4. Adequate funding can overcome implementation gaps in CSA. The way forward is linking climate and agricultural financing and making use of innovative financing sources. At the same time, investments in climatefriendly agriculture are an opportunity for the private sector.

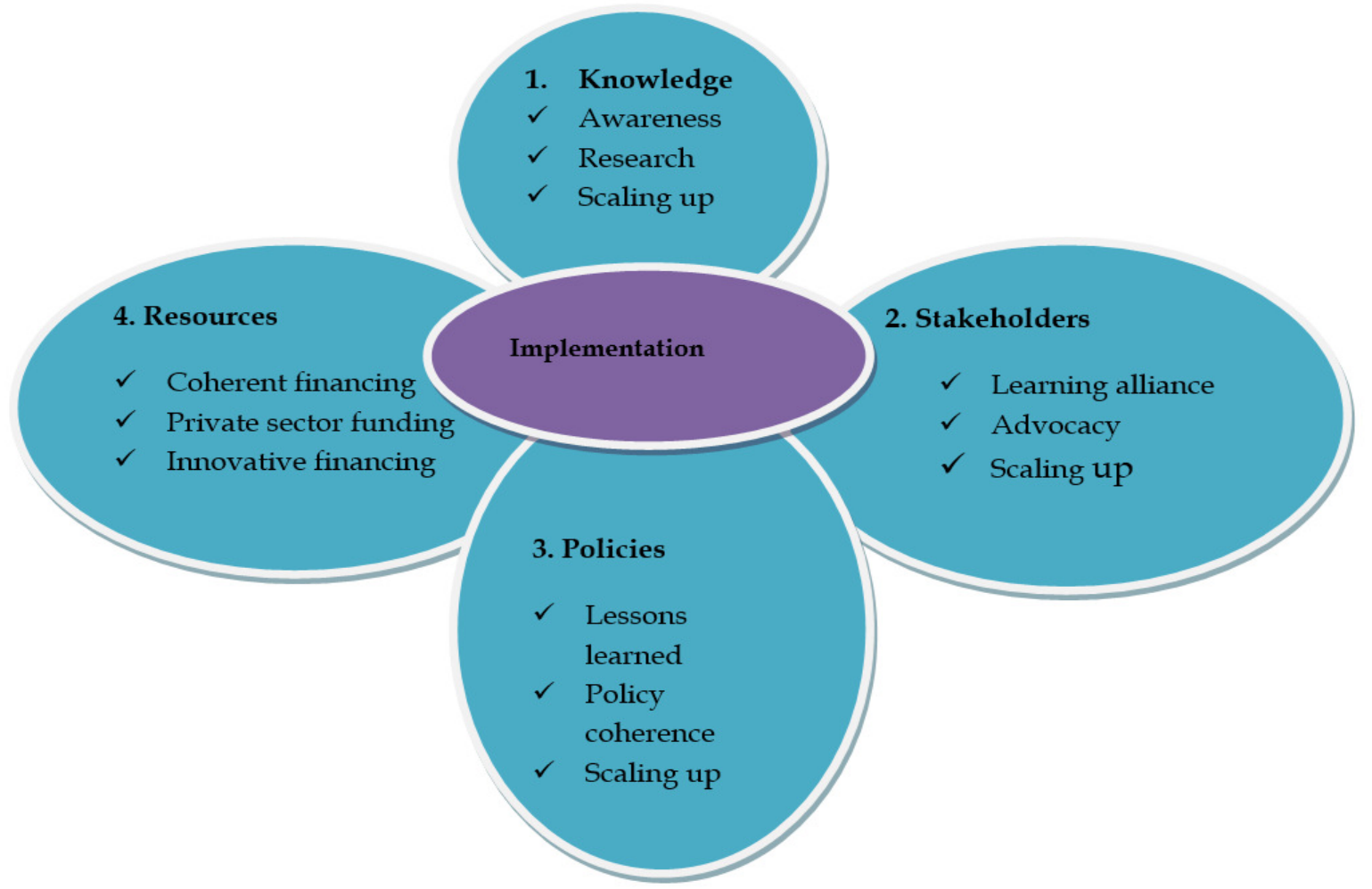

Figure 3 four-step bottom-up processes to make agriculture climate-smart (CSA implementation). Source (Knaepen et al., 2015). 


\section{Conclusion}

The global population is expected to reach 9 billion in 2050 which will also require probably doubling the current food production in order to meet the demand. However this increase is supposed to be achieved, there is a big challenging issue of climate change. So interventions are required to feed the rapidly growing world's population especially in developing countries. Therefore, the need for adaptation and mitigation measures is now stronger options to meet food requirements in the face of an ever changing climate. In this regard, climate smart agriculture (CSA) approach offers a viable and sustainable solution for the achievement of optimal crop yield of a high quality with low negative environmental effects. CSA is "agriculture that sustainably increases productivity, enhances resilience, reduces/removes GHGs where possible, and enhances achievement of food security national and development goals".

There are several approaches and practices which contribute to CSA by enhancing climate change adaptation and/or mitigation while leading to sustainable crop production at the same time. These practices include ecosystem-based approaches; organic agriculture, conservation agriculture (promoting of mulching and cover cropping, enhancing crop diversification and crop rotation), integrated weeds and pests management, water and irrigation management, soil and land use management, promotion of legumes cultivation, agro forestry and so on. However, adoption of CSA approaches and practices faces a number challenges related to the conceptual understanding practice, policy environment and financing of the approach is possible to adopt and implement it. A good understanding of what these barriers are and how they impinge on adoption of CSA practices and approaches is essential solution to implement. Therefore, CSA approaches and practices are important to provide triple wines of increasing productivity and income, climate change adaptation and mitigation for sustainable crop production.

\section{Reference}

Ajayi O., Akinnifesi. F, Mullila-Mitti. J, Dewolf. J, Matakala. P and Kwesiga. F, 2008. 'Adoption, profitability, impacts and scaling-up of agroforestry technologies in southern African countries'.

Alvarez R. and Steinbach H.S., 2009. A review of the effects of tillage systems on some soil physical properties, water content, nitrate availability and crop yield in the argentine pampas. Soil and tillage research 104(1), 115.

Barnard James, Manyire Henry, Tambi Emmanuel and Bangali Solomon, 2015. Barriers to scaling up climate smart agriculture and strategies to enhance adoption in Africa Forum for Agricultural Research in Africa, Accra, Ghana.

Bayala J., Sileshi GW., Coe R., Kalinganire A., Tchoundjeu Z., Sinclair F. and Garrity D., 2012. Cereal yield response to conservation agriculture practices in dry lands of West Africa, a quantitative synthesis. Journal of arid environment 78: 13-25.

Bot A. and Benites J., 2001. Conservation agriculture. Case studies in Latin America and Africa. Rome: UN food and agriculture organization.

Campbell B M., Thornton P., Zougmore R., Asten P. V. and Lipper L., 2014. Sustainable intensification. What is its role in climate smart agriculture? Current opinion in environmental sustainability. science direct.

Dendooven L., Gutiérrez-Oliva VF., Patiño-Zúñiga L., Guido M. and Marsch R., 2012. Greenhouse gas emissions under conservation agriculture compared to traditional cultivation of maize in the central highlands of Mexico. Science of the total environment 431: 237-244.

Erenstein O., Sayre K., Wall P., Hellin J. and Dixon J., 2012. Conservation agriculture in maize- and wheat-based systems in the (subtropics: lessons from adaptation initiatives in South Asia, Mexico, and southern Africa. Journal of sustainable agriculture 36: 180-206.

FAO, 2010. "Climate-Smart" Agriculture Policies, Practices and Financing for Food Security, Adaptation and Mitigation, Rome.

FAO, 2012a. Using marginal abatement cost curves to realize the economic appraisal of climate-smart agriculture: policy options.

FAO, 2013. Climate-smart agricultural sourcebook, executive summary.

FAO, 2014. Submission by the food and agriculture organization of the united nations (FAO) to the united nations framework convention on climate change (UNFCCC) on issues relating to agriculture. Agricultural practices and technologies.

FAO, 2015. The impact of natural hazards and disasters on agriculture and food and nutrition security. A call for action to build resilient livelihoods, Rome:

Garrity D., 2004. "Agroforestry and the achievement of the millennium development goals." Agroforestry systems 61(1): 5-17(13).

Geerts S., Raes D., Garcia M., Vacher J., R. Mamani, J. Mendoza, J. Cusicanqui, and Taboada C., 2008. Introducing deficit irrigation to stabilize yields of quinoa (chenopodium quinoa willd.). European Journal of agronomy 28(3): 427-36. 
Govaerts B., Sayre K. and Deckers J., 2005. Stable high yields with zero tillage and permanent bed planting? Field crops research 94(1): 33-42.

Grainger-Jones E., 2011. Climate-smart smallholder agriculture: what's different? IFAD occasional paper No.3. Rome.

Howell T.A., 2001. Enhancing water use efficiency in irrigated agriculture. Agronomy journal 93(2): 281-89.

https://ccafs.cgiar.org/publications/learning-alliances-approach-building-multistakeholder-innovation-systems VkI3OmSrQ6U.

https://csa.guide/csa/. What-is-climate-smart-agriculture.

IPCC, 2007. Climate change 2007: mitigation of climate change Contribution of Working Group III to the Fourth Assessment Report of the IPCC. Cambridge, United Kingdom and New York.

Jansen, H.G., A. Rodriguez, A. Damon, J. Pender, J. Cheniern, and R. Schipper. 2006. Determinants of incomeearning strategies and adoption of conservation practices in hillside communities in rural Honduras. Agricultural systems 88(1): 92-110.

Knaepen H, Torres C and Rampa F., 2015. Making agriculture in Africa climate-smart from continental policies to local practices. Briefing note. European center for development policy management.

La Scala N., Bolonhezi D. and Pereira G., 2006. Short-term soil co2 emission after conventional and reduced tillage of a no-till sugar cane area in southern Brazil. Soil and tillage research 91(1-2): 244-48.

Laclau B.P. and Laclau J.P., 2009. Growth of the whole root system for a plant crop of sugarcane under rainfed and irrigated environments in Brazil. Field crops research 114(3): 351-60.

Lin B.B., 2011. Resilience in agriculture through crop diversification. Adaptive management for environmental change. Bioscience 61(3): 183-93.

Lin B.B., Perfecto I. and Vandermeer J., 2008. Synergies between agricultural intensification and climate change could create surprising vulnerabilities for crops. Bioscience 58(9): 847-54.

McCarthy Nancy, 2014. Climate-smart agriculture in Latin America. Drawing on research to incorporate technologies to adapt to climate change. Inter-American Development Bank. Felipe Herrera Library. IDB Technical Note; 652.

Mertz O., Halsnæs K., Olesenm J. and Rasmussen K., 2009. Adaptation to climate change in developing countries. Environmental management 43(5): 743-52.

Milder JC., Majanen T. and Scherr SJ., 2011. Performance and potential of conservation agriculture for climate change adaptation and mitigation in Sub-Saharan Africa. Eco-agriculture discussion paper no. 6. Washington DC: Eco-agriculture partners.

Obalum S.E., Ezenne G., Watanabe Y. and Wakatsuki T., 2011. Contemporary global issue of rising water scarcity for agriculture: the quest for effective and feasible soil moisture and free-water surface conservation strategies. Journal of water resource and protection 3(3): 166-75.

Posthumus H., 2005. Adoption of terraces in the Peruvian Andes. Wageningen University and research centre.

Pretty J.N., Noble A. Bossio D., Dixon J., Hine R., Penning de Vries F. and Morison J., 2006. Resource-conserving agriculture increases yields in developing countries. Environmental science \& technology 40(4): 1114-119.

Reij C., Tappan G. and Smale M., 2009. "Re-greening the Sahel. Farmer-led innovation in Burkina Faso and Niger.

Rosenzweig, C., A. Iglesias, X. Yang, P.R. Epstein, and Chivian E., 2001. Climate change and extreme weather events; implications for food production, plant diseases, and pests. Global change \& human health 2(2): 90 104.

San Martin O., 2002. Water resources in Latin America and the Caribbean. Issues and options. IDB sustainable development department, environment division. Washington, DC: Inter- American Development Bank.

Sisti C. P., H. dos Santos R., Kohhann B., Alves S., Urquiaga and Boddey R.., 2004. Change in carbon and nitrogen stocks in soil under 13 years of conventional or zero tillage in southern Brazil. Soil and tillage research 76(1): 39-58.

Soto-Pinto L., I. Perfecto J., Castillo-Hernandez and Caballero-Nieto J., 2000. Shade effect on coffee production at the northern tzeltal zone of the state of Chiapas, Mexico. Agriculture, ecosystems \& environment 80(1): $61-69$.

Tantely R., Herintsitohaina R., Tovonarivo R., Narindra R., Tiana S., Andry.A, Marie Lucia. F, Stéphan. R, Sylvain. D, Falinirina. V, Bernard. L, Masse. D, Alain. A., 2015. Climate smart agriculture. Climate smart practices impact soil organic carbon storage in Madagascar. Global science conference.

Thierfelder C, Chisui JL, Gama M, Cheesman S, Jere ZD, Bunderson WT, Eash NS, Rusinamhodzi L., 2013. Maize-based conservation agriculture systems in Malawi: long-term trends in productivity. Field Crops Research 142: 47-57.

Thornton PK and Gerber P., 2010. Climate change and the growth of the livestock sector in developing countries. Mitigation and adaptation strategies for global change, 15:169-184.

UNESCO (United Nations Educational, Scientific and Cultural Organization), 2011. Climate change starter's guidebook places de Fontenoy, 75352 Paris 07 SP, France and the United Nations environment programme 
15 rue de Milan.

Verchot L.V., M. van Noordwijk, S. Kandji, T. Tomich and Ong C., 2007. Climate change. Linking adaptation and mitigation through agroforestry. Mitigation and adaptation strategies for global change 12: 901-918.

Wollenberg E., Higman, S., Seeberg-Elverfeldt, H., Neely, C., Tapio-Bistrom, M-L and Neufeldt H., 2012 b. Helping smallholder farmers mitigate climate change. CCAFS Policy Brief 5. Copenhagen, Denmark.

Zomer R.J., Trabucco A., Coe R. and Place F., 2009. Trees on farm. Analysis of global extent and geographical patterns of agroforestry. ICRAF working paper no. 89. Nairobi, Kenya: World agroforestry centre. 